\title{
PREVALENCE AND DISTRIBUTION OF MALARIA BY SEX, AGE GROUPS AND SPECIES IN YEAR 2019 IN SUSPECTED MALARIAL POPULATION OF DISTRICT D.I.KHAN, PAKISTAN
}

Syed Wasif Ali Naqvi', Shahzil Saeed', Ansar Rafique', Muhammad Hasnain Saeed ${ }^{1}$, Nisar Khan², Amanullah Khan', Muhammad Ubaidullah', Muhammad Usman Farooq', Hafiz Abdul Hadi Khan', Roohan Ahmad', Jawad Wajid', Masil Khan Baloch', Aayan Elahi Zaheer', Faizan Rabbani'

${ }^{1}$ Students, Departments of ${ }^{2}$ Medicine \& ${ }^{3}$ Community Medicine, Gomal Medical College, D.I.Khan, Pakistan

\begin{abstract}
Background: Malaria is communicable disease that exists worldwide and is a cause of morbidity and mortality. Our objectives were to determine the prevalence and distribution of malaria by sex, age groups and species in year 2019 in suspected malarial population of District D.I.Khan, Pakistan.

Materials \& Methods: This cross-sectional study was conducted in Department of Community Medicine, Gomal Medical College, D.I.Khan, Pakistan from October 1, 2020 to October 31, 2020. The data for malaria was retrieved from office of Frontier Primary Healthcare, D.I.Khan for 2019. A sample of 108,849 was calculated from population at risk of $1,306,655$, with 0.258154 margin of error, $99 \% \mathrm{Cl}$ and $13.843 \%$ assumed prevalence of malaria. Sex, age groups, species and presence of malaria were our four nominal variables. Prevalence and distribution were described by count and percentage with $95 \%$ confidence intervals. Four hypotheses for prevalence and distribution were verified by chi-square goodness of fit test.

Results: Out of a sample of 108,849 suspected malarial cases, 9,568 (8.79\%, 95\%Cl, 8.62-8.95\%) were positive. Out of 9,568 positive cases, 5,406 (4.97\%) were men and 4,162 (3.82\%) women, 1,062 (0.98\%) in age group up to 5 years and $8,506(7.81 \%)$ in age group $>5$ years and $9,121(8.38 \%)$ were Plasmodium vivax, $437(0.40 \%)$ were Plasmodium falciparum and $10(0.009 \%)$ were mixed malarial infections. Our prevalence of malaria $8.79 \%$ was lower to $13.843 \%$ expected $(p=<.00001)$. Our distribution across $\operatorname{sex}(p=<.00001)$, age groups $(p=.03231)$ and species $(p=<.00001)$ were not similar to expected.

Conclusion: The prevalence of malaria in year 2019 in suspected malarial population of District D.I.Khan, Pakistan was $8.79 \%$. The prevalence was lower than expected for our population. The prevalence was higher for men, older age group (>5 years) and for Plasmodium vivax. The prevalence for men was higher than expected for men and vice versa for women. The prevalence for age group up to 5 years was higher than expected for age group up to 5 years and vice versa for age group $>5$ years. The prevalence for Plasmodium vivax was higher than expected for Plasmodium vivax and vice versa for Plasmodium falciparum and mixed cases.
\end{abstract}

KEY WORDS: Malaria; Plasmodium; Plasmodium vivax; Plasmodium falciparum; Prevalence; Sex; Age groups; Species; Mortality, Morbidity.

Cite as: Naqvi SWA, Saeed S, Rafique A, Saeed MH, Khan N, Khan A, et al. Prevalence and distribution of malaria by sex, age groups and species in year 2019 in suspected malarial population of district D.I.Khan, Pakistan. Gomal J Med Sci 2020 Oct-Dec; 18(4):164-73. https://doi.org/10.46903/gjms/18.04.938

Corresponding Author:

Syed Wasif Ali Naqvi

Student, Gomal Medical College

D.I.Khan, Pakistan

E-mail: syedwasifali50@gmail.com

Date Submitted: $\quad 05-11-2020$

Date Revised: $\quad 02-12-2020$

Date Accepted: $\quad 10-12-2020$

\section{INTRODUCTION}

\subsection{Background}

Malaria is communicable disease that exists worldwide. ${ }^{1}$ Malaria is caused by five species from genus plasmodium. Yearly, around 3 billion people are at risk of getting infected. About half of the people live in the 87 countries where it is prevalent leading to a huge risk factor.

For the year 2015, globally 429,000 deaths and 212 
million cases were reported, while in 2019 , the toll was 229 million cases and 409,000 deaths. These cases were mostly from 87 countries where malaria is endemic. ${ }^{2}$ Malaria cases were reduced from 80 per 1,000 in year 2000 to around 57 per 1,000 in year 2019.

In the following two tables, we have presented the burden of malaria globally, then in Eastern Mediterranean Region (EMR) and lastly in Pakistan for the years 2000 and 2015, both for deaths (Table 1.1.1) and DALYs (disability-adjusted life years). ${ }^{3,4}$ (Table 1.1.2)

Kachur, et al. ${ }^{5}$ reported from Haiti for period from 23 to 27 October 1995 with prevalence of malaria as 72 $(3.993 \%)$ out of $1,803\left(72^{\star} 100 / 1803=3.993\right)$ suspected malarial cases. The distribution by age was 12 $(0.665 \%)$ for up to 5 years $(12 * 100 / 1803=0.665)$ and $60(3.328 \%)$ for above 5 years $(60 * 100 / 1803=3.328)$. All $72(100 \%)$ positive were Plasmodium falciparum species.

Regasa ${ }^{6}$ reported a study from Ethiopia for the period from January to April 2010, with overall frequency of malaria as $28(7 \%)$ out of 400 suspected malarial patients. Distribution by sex was more for males 16 (4\%) than females 12 (3\%). Distribution by species was 18 (4.5\%) for Plasmodium falciparum $\left(18^{*} 100 / 400=4.5\right)$, $7(1.75 \%)$ for Plasmodium vivax $(7 * 100 / 400=1.75)$ and remaining $3(0.75 \%)$ showed mixed infections $(3 * 100 / 400=0.75)$.
Abah, et al. ${ }^{7}$ reported in 2015 , the frequency of malarial infection as 190 (63.333\%) out of 300 $(190 * 100 / 300=63.333)$ primary school children in Bayelsa State, Nigeria. The distribution by sex was more $108(36 \%)$ for males $(108 * 100 / 300=36)$ than $82(27.333 \%)$ females $\left(82^{*} 100 / 300=27.333\right)$.

In the Eastern Mediterranean Region of $\mathrm{WHO}^{8}$, malarial cases have dropped by $26 \%$ from 7 million cases in year 2000 to 5 million cases in year 2019 . Unfortunately, Pakistan (21\%) and Sudan (59\%) account for $80 \%$ of all these cases. However, seven countries have reduced cases by greater than $75 \%$ which include Afghanistan, Iran, Iraq, Morocco, Oman, Saudi Arabia and Syria. In 2015, Saudi Arabia and Iran had only 83 and 187 cases respectively.

EMR has around 14 million malaria cases per year. Here, Plasmodium malariae and Plasmodium vivax contribute the risk to about $45 \%$ of the population, while $15 \%$ are affected by Plasmodium vivax. Malaria is endemic in all areas of Afghanistan having altitude lower than 1,500 meters. Here Plasmodium vivax contributes $80-90 \%$, while Plasmodium falciparum contributes the rest. In Islamic Republic of Iran, around $66 \%$ area is free from malaria, $12 \%$ area is affected by Plasmodium vivax and $6 \%$ by Plasmodium falciparum.

Al Mekhlafi, et al. ${ }^{9}$ reported the prevalence of malaria in highlands of Yemen during the period from June 2008 to March 2009 as 78 (17.1428\%) out of 455

Table 1.1.1: WHO Global, EMR \& Pakistan data for malaria deaths for years 2000 and 2015

\begin{tabular}{|c|c|c|c|c|c|}
\hline \multirow{2}{*}{ Deaths 2000-2015 } & \multirow{2}{*}{ Total Population } & \multirow{2}{*}{$\begin{array}{l}\text { Total Deaths } \\
\text { All causes }\end{array}$} & \multicolumn{3}{|c|}{ Malaria Deaths } \\
\hline & & & Malaria Deaths & $\%$ of all deaths & 20 leading causes \\
\hline Global 2015 & $7,344,362,000$ & $56,441,319$ & 439,026 & 0.7778 & - \\
\hline Global 2000 & $6,122,410,000$ & $52,134,566$ & 858,896 & 1.6474 & $14^{\text {th }}$ \\
\hline EMR 2015 & $643,784,000$ & $4,023,088$ & 7,350 & 0.1826 & - \\
\hline EMR 2000 & $467,911,000$ & $3,400,392$ & 14,537 & 0.4275 & - \\
\hline Pakistan 2015 & $188,925,000$ & $1,370,800$ & 800 & 0.0583 & - \\
\hline Pakistan 2000 & $138,250,000$ & $1,203,200$ & 4,100 & 0.3407 & - \\
\hline
\end{tabular}

Table 1.1.2: WHO Global, EMR \& Pakistan data for malaria DALYs for years 2000 and 2015

\begin{tabular}{|l|c|c|c|c|}
\hline \multirow{2}{*}{ DALYs 2000-2015 } & \multirow{2}{*}{ Total DALYs All causes } & \multicolumn{3}{|c|}{ Malaria DALYs } \\
\cline { 3 - 5 } & & Malaria DALYs & \% of Total DALYs & 20 leading causes \\
\hline Global 2015 & $2,668,295,388$ & $38,519,926$ & 1.4436 & $18^{\text {th }}$ \\
\hline Global 2000 & $2,805,625,771$ & $76,565,138$ & 2.7289 & $8^{\text {th }}$ \\
\hline EMR 2015 & $219,793,780$ & 574,039 & 0.2611 & - \\
\hline EMR 2000 & $226,450,716$ & 626,413 & 0.2766 & - \\
\hline Pakistan 2015 & $87,503,350$ & 55830 & 0.0638 & - \\
\hline Pakistan 2000 & $83,199,256$ & 262,306 & 0.3152 & - \\
\hline
\end{tabular}


$(78 * 100 / 455=17.1428)$ febrile patients. The distribution by sex was higher as $48(10.5494 \%)$ males $\left(48^{*} 100 / 455=10.5494\right)$ than $30(6.5934 \%)$ females $(30 * 100 / 455=6.5934)$. The distribution by species was $75(16.4835 \%)$ for Plasmodium falciparum $(75 * 100 / 380=16.4835), 2(0.4395 \%)$ for Plasmodium vivax $(2 * 100 / 455=0.4395), 1(0.2197 \%)$ for Plasmodium malariae $(1 * 100 / 455=0.2197)$ and no mixed infections were observed.

Eshag, et al. ${ }^{10}$ reported the prevalence of malaria from Al-Geneina city, Sudan during the period from July 2018 to December 2018 as 232 $(61.0526 \%)$ positive out of 380 suspected patients $(232 * 100 / 380=61.0526)$. The distribution by sex was higher 126 (33.1578\%) in females $(126 * 100 / 380=33.1578)$ than $106(27.8947 \%)$ in males $(106 * 100 / 380=27.8947)$.

Singh, et al. ${ }^{11}$ reported the prevalence of malarial infection from January to December 2013 from Navi Mumbai, India as $809(16.584 \%)$ out of 4,878 suspected malarial cases $(809 * 100 / 4878=16.584)$. The distribution by sex was more as $516(10.578 \%)$ in males $(516 * 100 / 4878=10.578)$ than $293(6.006 \%)$ in females $(293 * 100 / 4878=6.006)$. The distribution by species was $443(9.081 \%)$ for Plasmodium vivax $(443 * 100 / 4878=9.081), 144(2.952 \%)$ for Plasmodium falciparum $(144 * 100 / 4878=2.952)$ and 222 $(4.551 \%)$ for mixed $\left(222^{*} 100 / 4878=4.551\right)$ cases.

Malaria is still a leading cause of morbidity and mortality in Pakistan ${ }^{12}$ like many other countries. It is a risk for health of millions of peoples and is one of the six priority communicable diseases. Pakistan is a high burden country for malaria and has estimated one million and confirmed 300,000 cases annually. The distribution is more for Plasmodium vivax than Plasmodium falciparum and mixed cases. Malaria is a seasonal infection and therefore epidemic outbreaks are not unusual in certain regions like Khyber Pakhtunkhwa, Sindh and Balochistan provinces. Khyber Pakhtunkhwa has three endemic districts; Bannu, Lakki Marwat and D.I.Khan. June to September have peaks for P.vivax, April to June have relapsing cases, with Plasmodium falciparum on peak during August-December in these regions.

Directorate of Malaria Control (DMC), Pakistan ${ }^{13}$ has reported 374,513 confirmed cases of malaria out of 6.5 million suspected and tested malarial cases for the year 2018, giving an overall prevalence rate of $5.7617 \%(374,513 * 100 / 6,500,000=5.7617)$ for Pakistan (including all four provinces, Tribal districts \& AJK), also called TPR (test positivity rate). The distribution by geographic locations (places) was as; 129,085 (1.9859\%) for Sindh province $(129,085 * 100 / 6,500,000=1.9859)$, $115,995(1.7845 \%)$ for Khyber Pakhtunkhwa $(115,995 * 100 / 6,500,000=1.7845), 65,853(1.0131 \%)$ for Tribal districts $(65,853 * 100 / 6,500,000=1.0131)$, $61,510(0.9463 \%)$ for Balochistan
$(61,510 * 100 / 6,500,000=0.9463), 1,875(0.0289 \%)$ for Punjab $\left(1,875^{*} 100 / 6,500,000=0.0289\right)$ and 195 $(0.0030 \%)$ for AJK $(195 * 100 / 6,500,000=0.0030)$. The distribution by species was as; 314,574 (4.8396\%) for Plasmodium vivax $(314,574 * 100 / 6,500,000=4.8396)$, $55,639(0.8560 \%)$ for Plasmodium falciparum $(55,639 * 100 / 6,500,000=0.8560)$ and 4,300 $(0.0661 \%)$ mixed $(4,300 * 100 / 6,500,000=0.0661)$ cases.

Najeeb, et al..$^{14}$ reported the prevalence of malaria as $13.81 \%$ from Khyber Pakhtunkhwa, Pakistan by random effect model from combined estimate of 18 studies searched through databases from 2003 to 2017.

According to a study by Qureshi, et al., ${ }^{15}$ the overall prevalence of malaria in three endemic districts of Khyber Pakhtunkhwa province, Pakistan; Bannu, Lakki Marwat and D.I.Khan was $13.8430 \%$ $(4,297 * 100 / 31,041=13.843)$ with 4,297 positive cases from a sample of 31,041 patients during August to October 2018, using RDT as diagnostic test. The prevalence of malaria was $1,735(5.5894 \%)$ in Bannu $\left(1,735^{\star} 100 / 31,041=5.5894\right), 1,317(4.2428 \%)$ in Lakki Marwat $(1,317 * 100 / 31,041=4.2428)$ and 1,245 $(4.0108 \%)$ in D.I.Khan $(1,245 * 100 / 31,041=4.0108)$. The distribution by sex was more 2,202 (7.0939\%) for females $(2,202 * 100 / 31,041=7.0939)$ than 2,095 $(6.7491 \%)$ males $(2,095 * 100 / 31,041=6.7491)$. The distribution by age groups was high 3,849 (12.3997\%) for $>5$ years $(3,849 * 100 / 31,041=12.3997)$ than $448(1.4433 \%)$ for age group up to 5 years $(448 * 100 / 31,041=1.4433)$. The distribution by species was $3,970(12.7895 \%)$ for Plasmodium vivax $(3,970 * 100 / 31,041=12.7895), 204(0.6572 \%)$ for Plasmodium falciparum $(204 * 100 / 31,041=0.6572)$ and $123(0.3963 \%)$ for mixed infections $(123 * 100 / 31,041=0.3963)$.

Fatima, et al. ${ }^{16}$ collected a sample of 2,033 suspected malaria cases from Bannu, FATA, Karak and Lakki Marwat; southern districts of Khyber Pakhtunkhwa province, Pakistan from March to October 2013 and noted the prevalence of malaria as $429(21.10 \%)$ cases $(429 * 100 / 2,033=21.1)$. Distribution by species was $343(16.871 \%)$ for Plasmodium vivax, 47 (2.311\%) for Plasmodium falciparum and 39 (1.918\%) for mixed infections.

Important Note: Directorate of Malaria Control (DMC), Pakistan ${ }^{13}$ has calculated percentage for prevalence correctly by taking the total sample of $6,500,000$ (6.5 million) as denominator. But percentages for distribution by places and species are not calculated correctly as DMC has taken 374,513 positive cases of malaria as denominator here. DMC had to take here also the total sample of $6,500,000(6.5$ million) as denominator. The prevalence rates given as percentages for different provinces and species are calculated correctly by us as shown above ${ }^{13}$ by using the total sample of $6,500,000$ (6.5 million) as 
denominator. Therefore there is gross difference in prevalence rates between the data in the DMC report and the data calculated and reported here by us. The same is true for other seven studies cited here by Kachur, et al. ${ }^{5}$, Regassa. ${ }^{6}$, Abah, et al. ${ }^{7}$, Al Mekhlafi, et al. ${ }^{9}$, Eshag, et al..$^{10}$, Singh, et al. ${ }^{11}$ and Qureshi, et al. ${ }^{15}$

1.2 Research Problems (RPs), Knowledge Gaps (KGs), Justification and Research Questions (RQs)

Unawareness regarding the prevalence and distribution of malaria by sex, age groups and species in year 2019 in suspected malarial population of District D.I. Khan, Pakistan were our four RPs. Unavailability of data regarding these research problems were our four KGs and justification for the study. What is the prevalence and distribution of malaria by sex, age groups and species in year 2019 in suspected malarial population of District D.I.Khan, Pakistan were our four RQs.

\subsection{Research Objectives (ROs)}

The objectives of our research project were to determine:

R01: The prevalence of malaria in year 2019 in suspected malarial population of District D.I. Khan, Pakistan.

RO2: The distribution of malaria by sex in year 2019 in suspected malarial population of District D.I. Khan, Pakistan.

RO3: The distribution of malaria by age groups in year 2019 in suspected malarial population of District D.I. Khan, Pakistan.

R04: The distribution of malaria by species in year 2019 in suspected malarial population of District D.I. Khan, Pakistan.

\subsection{Research (Null) Hypotheses}

Following were four null hypotheses of our research project that will answer our research questions, which will fill our knowledge gaps and will solve our research problems.

$\mathbf{H}_{01}$ : The observed prevalence of malaria in year 2019 is same as expected in suspected malarial population of District D.I. Khan, Pakistan.

$\mathbf{H}_{02}$ : The observed distribution of malaria in year 2019 by sex is same as expected in suspected malarial population of District D.I. Khan, Pakistan.

$\mathbf{H}_{\mathrm{O} 3}$ : The observed distribution of malaria by age groups in year 2019 is same as expected in suspected malarial population of District D.I. Khan, Pakistan.

$\mathbf{H}_{\mathrm{O} 4}$ : The observed distribution of malaria by species in year 2019 is same as expected in suspected malarial population of District D.I. Khan, Pakistan.

1.6 Significance: Allocation of resources depends upon the magnitude of the problem. Having overall magnitude (prevalence) \& group-wise magnitude (distribution) of malaria in our population of interest, the service providers (government \&/or NGOs) may be able to allocate their resources to combat malaria optimally. Further, this study will also provide baseline data for further research to explore the cause and effect relationships.

\section{MATERIALS AND METHODS}

2.1 Study Design, Settings \& Duration and approval of the Project: This cross-sectional study was conducted in the Department of Community Medicine, Gomal Medical College, D.I.Khan, Pakistan from October 1, 2020 to October 31, 2020. The technical approval of this project was granted by the Research Review Committee of the institute. Ethical approval was not required as it didn't involve manipulation/ interaction with humans, as the data was already collected and saved in the computer. This project was part of the studies for $4^{\text {th }}$ year MBBS and was supervised by Dr. Muhammad Marwat and co-supervised by Dr. Nisar Khan and Dr. Amanullah Khan.

2.2 Population, Sample Size \& Technique and Sample Selection: Dera Ismail Khan, ${ }^{17}$ often abbreviated as D.I.Khan is the $4^{\text {th }}$ populous district in Khyber Pukhtunkhwa; a province in the north-west of Pakistan. The district has an area of $9,334 \mathrm{~km}^{2}$. It is situated on the west bank of the Indus River, about 300 kilometers to the south of the provincial capital Peshawar, and 290 kilometers southwest of Islamabad. Its latitude is $31.8626^{\circ}$ and longitude is $70.9019^{\circ}$. Its weather is four seasonal with temperature range of $5^{\circ} \mathrm{C}$ to $41^{\circ} \mathrm{C}$, humidity range $10 \%-29 \%$ and wind range at speed of $9-30 \mathrm{~km} / \mathrm{h}$. Its population was 1,627,132 according to 2017 census. Based in District Health Office, D.I.Khan, Frontier Primary Healthcare $(\mathrm{FPHC})^{18}$ is an NGO registered with government of Pakistan in January 1995, providing preventive, diagnostic and curative facilities through 78 health facilities in District D.I.Khan. These include 59 public health facilities (14 microscopic and 45 Rapid Diagnostic Test centers) and 19 private health facilities (all RDT centers). These centers cover population of $1,306,655$ of District D.I.Khan. Out of this population, a sample size of 108,849 was calculated with $0.258154 \%$ margin of error, $99 \%$ confidence lev$\mathrm{el}$, assumed prevalence of malaria $13.843 \%{ }^{15}$ using an online calculator Raosoft ${ }_{\circledast}^{19}$ through consecutive non-probability sampling technique.

Inclusion Criteria: All population of district D.I. Khan was eligible for inclusion.

Exclusion Criteria: There were no exclusion criteria.

2.3 Conduct of Procedure: Frontier Primary Healthcare $(\mathrm{FPHC})$ maintains the record of malaria cases at District Health Office, D.I.Khan. The data for malaria was retrieved from this office in Excel spreadsheet for the period from $1^{\text {st }}$ January 2019 to $31^{\text {st }}$ December 2019.

2.4 Data Collection Plan: Sex (men and women), age groups (up to 5 years and $>5$ years) and spe- 
cies (P.vivax, P.falciparum and mixed) were three demographic and presence of malaria (yes and no) was one research variable (attributes), all on nominal scale.

\subsection{Data Analysis Plan}

2.5.1 Descriptive Statistics and Estimation of Parameters: The prevalence \& distribution for the sample were described by count and percentages and for population by estimated parameters as confidence intervals $(\mathrm{Cl})$ for proportions at $95 \%$ confidence level through normal approximation method, using online statistical calculator. ${ }^{20}$

The comparison for prevalence/ distribution between the attributes/ groups will be based on Cls. If the Cls overlap, there is no difference, otherwise different (higher or lower).

2.5.2 Hypotheses Testing: Observed, expected and adjusted expected counts and percentages for frequency and distribution by sex, age groups and species were calculated. One hypothesis $\left(\mathrm{H}_{01}\right)$ for frequency of malaria and three hypotheses $\left(\mathrm{H}_{02}\right.$ $\mathrm{H}_{03} \& \mathrm{H}_{04}$ ) for its distribution by sex, age groups and species were verified separately by chi-square goodness-of-fit test. Observed counts, expected counts, their difference, test statistics, degree of freedom and $\mathrm{p}$-value were given at alpha .05 by an online statistical calculator. ${ }^{21}$

\section{RESULTS}

\subsection{Descriptive Analysis \& Estimation of Parameters}

3.1.1 Prevalence of malaria in suspected malarial population: Out of 108,849 suspected malarial patients, 9,568 (8.79\%) had malaria, while 99,281 $(91.21 \%)$ had no malaria. Estimated prevalence in population lies between $8.62 \%$ and $8.95 \%$ with $95 \%$ $\mathrm{Cl}$ as shown below. (Table 3.1.1)

3.1.2 Distribution of positive cases of malaria by sex, age groups and species: The distribution of positive cases of malaria by sex, age groups and species in suspected malarial population is shown in Table 3.1.2. Out of 9,568 (8.79\%) positive malarial cases, 5,406 (4.97\%) were men and 4,162 (3.82\%) women, $1,062(0.98 \%)$ were in age group up to 5 years and $8,506(7.81 \%)$ in age group of $>5$ years, 9,121 (8.38\%) were Plasmodium vivax, 437 (0.40\%) were Plasmodium falciparum and $10(0.0091 \%)$ were mixed cases.

Here the prevalence of malaria in sample and its estimated prevalence in population as based upon

Table 3.1.1: Prevalence of malaria in year 2019 in suspected malarial population of District D.I.Khan, Pakistan $(n=108,849)$

\begin{tabular}{|l|l|c|c|c|c|}
\hline \multirow{2}{*}{ Variable } & \multirow{2}{*}{ Attributes } & \multicolumn{2}{|c|}{ Sample statistics } & \multicolumn{2}{|c|}{$95 \%$ Cl for proportion } \\
\cline { 3 - 6 } & & Count & Percentage & Lower & Upper \\
\hline \multirow{3}{*}{$\begin{array}{l}\text { Presence of } \\
\text { Malaria }\end{array}$} & Yes & 9,568 & $8.79 \%$ & 8.62 & 8.95 \\
\cline { 2 - 6 } & No & 99,281 & $91.21 \%$ & 91.04 & 91.37 \\
\cline { 2 - 6 } & Total & 108,849 & $100 \%$ & \multicolumn{2}{|c}{ Population parameter } \\
\hline
\end{tabular}

Table 3.1.2: Distribution of positive cases of malaria by sex, age groups and species in year 2019 in suspected malarial population of District D.I.Khan, Pakistan $(n=9,586 / 108,849)$

\begin{tabular}{|c|c|c|c|c|c|}
\hline \multirow{2}{*}{ Variables } & \multirow{2}{*}{ Attributes } & \multicolumn{2}{|r|}{ Sample statistics } & \multicolumn{2}{|c|}{ 95\% Cl for proportion } \\
\hline & & Count & Percentage & Lower & Upper \\
\hline \multirow{2}{*}{ Sex } & Men & 5,406 & $4.97 \%(5,406 * 100 / 108,849=4.9665)$ & 4.83 & 5.09 \\
\hline & Women & 4,162 & $3.82 \%(4,162 * 100 / 108,849=3.8236)$ & 3.70 & 3.93 \\
\hline \multirow{2}{*}{ Age groups } & Up to 5years & 1,062 & $0.98 \%(1,062 * 100 / 108,849=0.9756)$ & 0.91 & 1.03 \\
\hline & $>5$ years & 8,506 & $7.81 \%(8,506 * 100 / 108,849=7.8145)$ & 7.65 & 7.97 \\
\hline \multirow{3}{*}{$\begin{array}{l}\text { Parasite spe- } \\
\text { cie }\end{array}$} & P.vivax & 9,121 & $8.38 \%(9,121 * 100 / 108,849=8.3795)$ & 8.21 & 8.54 \\
\hline & P.falciparum & 437 & $0.40 \%(437 * 100 / 108,849=0.4015)$ & 0.36 & 0.43 \\
\hline & Mixed & 10 & $10 * 100 / 108,849=0.0091 \%$ & 0.0034 & 0.0148 \\
\hline \multicolumn{2}{|c|}{ Malaria Positive Cases } & 9,568 & $8.79 \%(9,568 * 100 / 108,849=8.7901)$ & 8.62 & 8.95 \\
\hline \multicolumn{2}{|c|}{ Malaria Negative Cases } & 99,281 & $91.21 \%(99,281 * 100 / 108,849=91.209)$ & 91.04 & 91.37 \\
\hline \multicolumn{2}{|l|}{ Total } & 108,849 & $100 \%$ & & \\
\hline
\end{tabular}


Cl was higher in men $(4.97 \%, 95 \% \mathrm{Cl} 4.83-5.09)$ than women $(3.82 \%, 95 \% \mathrm{Cl} 3.70-3.93)$ and higher in age group more $>5$ years $(7.81 \%, 95 \% \mathrm{Cl} 7.65-7.97)$ than age group up to 5 years $(0.98 \%, 95 \% \mathrm{Cl} 0.91-1.03)$. The prevalence for specie Plasmodium vivax $(8.38 \%$, $95 \% \mathrm{Cl}$ 8.21-8.54) was highest than the specie Plasmodium falciparum $(0.40 \%, 95 \% \mathrm{Cl} 0.36-0.43)$ and mixed cases $(0.009 \%, 95 \% \mathrm{Cl} 0.0034-0.0148)$.

\subsection{Hypotheses Testing:}

3.2.1 Observed vs. expected prevalence of malaria $\left(\mathbf{H}_{01}\right)$

Our observed counts for the presence of malaria (yes: no) were 9,568: 99,281 from a sample of 108,849 against expected counts of 4,297: 26,744 from a sample of 31,041 as reported by Qureshi, et al. ${ }^{15}$ With different sample sizes/ denominators, these were not comparable. Hence the expected counts and expected percentages were adjusted for a sample of 108,849 . For comparison, the expected counts were calculated to be $15,067: 93,782$. Adjusted expected percentages came similar to expected percentages. (Table 3.2.1.1)

Chi-square goodness of fit test showed $p$-value less than .05 alpha. $\mathrm{H}_{01}$ was declared as false and hence rejected; showing that the observed prevalence was not similar to the expected prevalence. Simply, the prevalence of $8.79 \%$ of malaria in our population was lower than what we were expecting from the adjusted expected counts and adjusted expected percentages of $13.84 \%$ from the study by Qureshi, et al. ${ }^{15}$ (Table 3.2.1.2)

3.2.2 Observed vs. expected distribution of malaria by sex $\left(\mathrm{H}_{02}\right)$

Our observed distribution for men versus women was 5,406: 4,162 out of 9,568 positive cases from a sample of 108,849 suspected malarial patients against expected counts of 2,095: 2,202 out of 4,297 positive cases from a sample of 31,041 from study by Qureshi, et al. ${ }^{15}$ With different sample sizes/ denominators, these were not comparable. Hence the expected counts and expected percentages were adjusted for a sample of 108,849 . The expected counts were replaced by 4,665: 4,903 and expected percentages were replaced by $4.29 \%: 4.50 \%$. (Table 3.2.2.1)

Chi-square goodness of fit test showed p-value less than .05 alpha. $\mathrm{H}_{02}$ was declared as false and hence rejected, showing that the observations did not match the expected values of the population. In simple words, our observed prevalence of malaria in men $4.97 \%$ was statistically higher than what we expected (adjusted expected) for men $4.29 \%$ \& our observed prevalence of malaria in women $3.82 \%$ was lower than what we expected (adjusted expected) for women $4.50 \%$ from the study by Qureshi, et al. ${ }^{15}$ (Table 3.2.2.2)

Table 3.2.1.1: Observed, expected and adjusted expected counts and percentages for distribution of malaria in year 2019 in suspected malarial population of District D.I.Khan, Pakistan $(n=108,849)$

\begin{tabular}{|l|c|c|c|c|c|c|}
\hline $\begin{array}{l}\text { Presence } \\
\text { of Malaria }\end{array}$ & $\begin{array}{c}\text { Observed } \\
\text { counts (O) }\end{array}$ & Observed \%ages & $\begin{array}{c}\text { Expected } \\
\text { counts }\end{array}$ & $\begin{array}{c}\text { Expected } \\
\text { \%ages }\end{array}$ & $\begin{array}{c}\text { Adjusted expected } \\
\text { counts (E) }\end{array}$ & $\begin{array}{c}\text { Adjusted expected } \\
\% \text { ages }\end{array}$ \\
\hline Yes & 9,568 & $\begin{array}{c}9,568^{*} 100 / \\
108,849=8.79 \%\end{array}$ & 4,297 & $13.84 \%$ & $\begin{array}{c}4,297^{\star} 108,849 / \\
31,041=15,067\end{array}$ & $\begin{array}{c}15,067^{\star} 100 / \\
108,849=13.84 \%\end{array}$ \\
\hline No & 99,281 & $\begin{array}{c}99,281 * 100 / \\
108,849=91.21 \%\end{array}$ & 26,744 & $86.16 \%$ & $\begin{array}{c}26,744^{\star} 108,849 / \\
31,041=93,782\end{array}$ & $\begin{array}{c}93,782^{\star} 100 / \\
108,849=86.16 \%\end{array}$ \\
\hline Total & 108,849 & $100 \%$ & 31,041 & $100 \%$ & 108,849 & $100 \%$ \\
\hline
\end{tabular}

Table 3.2.1.2: Observed vs. expected distribution of malaria in year 2019 in suspected malarial population of District D.I.Khan, Pakistan $(n=108,849)$

\begin{tabular}{|l|c|c|c|c|c|c|c|c|}
\hline Presence of Malaria & $\mathrm{O}$ & $\mathrm{E}$ & $\mathrm{O}-\mathrm{E}$ & $(\mathrm{O}-\mathrm{E})^{2}$ & $(\mathrm{O}-\mathrm{E})^{2} / \mathrm{E}$ & $\mathrm{X}^{2}$ & d.f. & $\mathrm{p}$-value \\
\hline Yes & 9,568 & 15,067 & $-5,499$ & $30,239,001$ & $2,006.96$ & $2,329.39$ & 1 & $<.00001$ \\
\hline No & 99,281 & 93,782 & 5,499 & $30,239,001$ & 322.43 & $\mathrm{H}_{01}$ rejected at alpha .05 \\
\hline Total & 108,849 & 108,849 & \multicolumn{5}{|c|}{ Chi-square goodness of fit test with Yates correction } \\
\hline
\end{tabular}

$\mathrm{O}=$ Observed count, $\mathrm{E}=$ Expected count, $\mathrm{X}^{2}=$ chi-square statistic, d.f. $=$ degree of freedom

Table 3.2.2.2 Observed vs. expected distribution of positive cases of malaria by sex in year 2019 in suspected malarial population of District D.I.Khan, Pakistan $(n=108,849)$

\begin{tabular}{|l|l|c|c|c|c|c|c|c|c|}
\hline Variable & Attributes & $\mathrm{O}$ & $\mathrm{E}$ & $\mathrm{O}-\mathrm{E}$ & $(\mathrm{O}-\mathrm{E})^{2}$ & $(\mathrm{O}-\mathrm{E})^{2} / \mathrm{E}$ & $\mathrm{X}^{2}$ & d.f. & p-value \\
\hline \multirow{3}{*}{ Sex } & Men & 5,406 & 4,665 & 741.00 & $549,081.00$ & 117.70 & 229.691 & 1 & $<.00001$ \\
\cline { 2 - 9 } & Women & 4,162 & 4,903 & -741.00 & $549,081.00$ & 111.99 & $\mathrm{H}_{02}$ rejected at alpha .05 \\
\hline \multicolumn{6}{|c|}{ Total } & 9,568 & 9,568 & \multicolumn{3}{c|}{ Chi-square goodness of fit test with Yates correction } \\
\hline
\end{tabular}


3.2.3 Observed vs. expected distribution of positive cases of malaria by age groups $\left(\mathrm{H}_{03}\right)$

Our observed distribution for age group up to 5 years versus $>5$ years were $1,062: 8,506$ out of 9,568 positive cases from a sample of 108,849 against expected counts of 448: 3,849 in age group of up to 5 years versus $>5$ years out of 4,297 positive cases of malaria in 31,041 patients as reported by Qureshi, et al. ${ }^{15}$ With different sample sizes/ denominators, these were not comparable. Hence the expected counts and expected percentages were adjusted for a sample of 108,849 . The expected counts of 448 : 3,849 were replaced by $998: 8,570$ and expected percentages were replaced by adjusted expected percentages as calculated $0.92 \%: 7.87 \%$ respectively and shown in Table 3.2.3.1

Chi-square goodness of fit test showed $p$-value less than .05 alpha. $\mathrm{H}_{03}$ was declared to be false and hence rejected, showing that the observations did not match the expected values of the population. It simply means that our observed prevalence of malaria in age group $>5$ years $7.81 \%$ was statistically lower than what we expected for age group > $>5$ years $7.87 \%$ (adjusted expected) \& our observed prevalence of malaria in age group up to 5 years $0.98 \%$ was higher than what we expected for age group up to 5 years 0.92\% (adjusted expected). (Table 3.2.3.2)

3.2.4 Observed vs. expected distribution of malaria by species $\left(\mathrm{H}_{04}\right)$

Our observed distribution of malaria by species for Plasmodium vivax, Plasmodium falciparum \& mixed cases were 9,121: 437: 10 respectively out of 9,568 positive cases from a sample of 108,849 suspected malarial patients against expected counts of 3,970: 204: 123 respectively out of 4,297 positive cases of malaria from study by Qureshi, et al. ${ }^{15}$ With different sample sizes/ denominators, these were not comparable. Hence the expected counts and expected percentages were adjusted for a sample of 108,849. The expected counts were replaced by 8,840: 454 : 274 respectively and expected percentages were replaced by $8.12 \%$ : $0.42 \%$ : $0.25 \%$ for Plasmodium vivax, Plasmodium falciparum \& mixed cases respectively. (Table 3.2.4.1)

Table 3.2.3.1: Observed, expected and adjusted expected counts and percentages for distribution of positive cases of malaria by age groups in year 2019 in suspected malarial population of District D.I.Khan, Pakistan $(n=108,849)$

\begin{tabular}{|l|c|c|c|c|c|c|}
\hline Presence of Malaria & $\begin{array}{c}\text { Observed } \\
\text { counts (O) }\end{array}$ & $\begin{array}{c}\text { Observed } \\
\text { \%ages }\end{array}$ & $\begin{array}{c}\text { Expected } \\
\text { counts }\end{array}$ & $\begin{array}{c}\text { Expected } \\
\% \text { ages }\end{array}$ & $\begin{array}{c}\text { Adjusted expect- } \\
\text { ed counts (E) }\end{array}$ & $\begin{array}{c}\text { Adjusted } \\
\text { expected \% }\end{array}$ \\
\hline $\begin{array}{l}\text { Positive cases in age } \\
\text { group up to 5 years }\end{array}$ & 1,062 & $\begin{array}{c}1,062^{*} 100 / \\
108,849=0.98 \%\end{array}$ & 448 & $\begin{array}{c}448^{*} 100 / \\
31,041=1.44 \%\end{array}$ & $\begin{array}{c}448 * 9,568 / \\
4,297=998\end{array}$ & $\begin{array}{c}998^{*} 100 / 108,849 \\
=0.92 \%\end{array}$ \\
\hline $\begin{array}{l}\text { Positive cases in age } \\
\text { group }>5 \text { years }\end{array}$ & 8,506 & $\begin{array}{c}8,506^{*} 100 / \\
108,849=7.81 \%\end{array}$ & 3,849 & $\begin{array}{c}3,849^{*} 100 / \\
31,041=12.40 \%\end{array}$ & $\begin{array}{c}3849 * 9,568 / \\
4,297=8,570\end{array}$ & $\begin{array}{c}8,570^{*} 100 / \\
108,849=7.87 \%\end{array}$ \\
\hline Total positive & 9,568 & $8.79 \%$ & 4,297 & $13.84 \%$ & 9568 & $8.79 \%$ \\
\hline
\end{tabular}

Table 3.2.3.2: Observed vs. expected distribution of positive cases of malaria by age groups in year 2019 in suspected malarial population of District D.I.Khan, Pakistan $(n=108,849)$

\begin{tabular}{|l|l|c|c|c|c|c|c|c|c|}
\hline Variable & Attributes & $\mathrm{O}$ & $\mathrm{E}$ & $\mathrm{O}-\mathrm{E}$ & $(\mathrm{O}-\mathrm{E})^{2}$ & $(\mathrm{O}-\mathrm{E})^{2} / \mathrm{E}$ & $\mathrm{X}^{2}$ & d.f. & $\mathrm{p}$-value \\
\hline \multirow{2}{*}{ Age groups } & Up to 5 years & 1,062 & 998 & 64.00 & $4,096.00$ & 4.10 & 4.582 & 1 & .03231 \\
\cline { 2 - 9 } & $>5$ years & 8,506 & 8,570 & -64.00 & $4,096.00$ & 0.48 & $\mathrm{H}_{03}$ rejected at alpha .05 \\
\hline \multicolumn{3}{|c|}{ Total } & 9,568 & 9,568 & \multicolumn{7}{c|}{ Chi-square goodness of fit test with Yates correction } \\
\hline
\end{tabular}

$\mathrm{O}=$ Observed count, $\mathrm{E}=$ Expected count, $\mathrm{X}^{2}=$ chi-square statistic, d.f.= degree of freedom

Table 3.2.4.1: Observed, expected and adjusted expected counts and percentages for distribution of positive cases of malaria by species in year 2019 in suspected malarial population of District D.I.Khan, Pakistan $(n=108849)$

\begin{tabular}{|l|c|c|c|c|c|c|}
\hline $\begin{array}{l}\text { Presence of } \\
\text { Malaria }\end{array}$ & $\begin{array}{c}\text { Observed } \\
\text { counts(O) }\end{array}$ & Observed \%ages & $\begin{array}{c}\text { Expected } \\
\text { counts }\end{array}$ & Expected \%ages & $\begin{array}{c}\text { Adjusted expect- } \\
\text { ed counts(E) }\end{array}$ & $\begin{array}{c}\text { Adjusted expect- } \\
\text { ed \% }\end{array}$ \\
\hline $\begin{array}{l}\text { Plasmodium } \\
\text { vivax }\end{array}$ & 9,121 & $\begin{array}{c}9,121^{*} 100 / \\
108,849=8.38 \%\end{array}$ & 3,970 & $\begin{array}{c}3,970 * 100 / \\
31,041=12.79 \%\end{array}$ & $\begin{array}{c}3,970 * 9,568 / \\
4,297=8,840\end{array}$ & $\begin{array}{c}8,840^{*} 100 / \\
108,849=8.12 \%\end{array}$ \\
\hline $\begin{array}{l}\text { Plasmodium } \\
\text { falciparum }\end{array}$ & 437 & $\begin{array}{c}437^{*} 100 / \\
108,849=0.40 \%\end{array}$ & 204 & $\begin{array}{c}204^{*} 100 / \\
31,041=0.65 \%\end{array}$ & $\begin{array}{c}204 * 9,568 / \\
4,297=454\end{array}$ & $\begin{array}{c}454^{*} 100 / \\
108,849=0.42 \%\end{array}$ \\
\hline Mixed & 10 & $\begin{array}{c}10^{*} 100 / \\
108,849=0.009 \%\end{array}$ & 123 & $\begin{array}{c}123^{*} 100 / \\
31,041=0.40 \%\end{array}$ & $\begin{array}{c}123^{*} 9,568 / \\
4,297=274\end{array}$ & $\begin{array}{c}274^{*} 100 / \\
108,849=0.25 \%\end{array}$ \\
\hline Total & 9,568 & $8.79 \%$ & 4,297 & $13.84 \%$ & 9,568 & $8.79 \%$ \\
\hline
\end{tabular}


Table 3.2.4.2: Observed vs. expected distribution of positive cases of malaria by species in year 2019 in suspected malarial population of District D.I.Khan, Pakistan $(n=108,849)$

\begin{tabular}{|c|c|c|c|c|c|c|c|c|c|}
\hline Variable & Attributes & $\mathrm{O}$ & $\mathrm{E}$ & O-E & $(\mathrm{O}-\mathrm{E})^{2}$ & $(\mathrm{O}-\mathrm{E})^{2} / \mathrm{E}$ & $x^{2}$ & d.f. & $\mathrm{p}$-value \\
\hline \multirow{3}{*}{$\begin{array}{l}\text { Parasite } \\
\text { specie }\end{array}$} & Plasmodium vivax & 9,121 & 8,840 & 281.00 & $78,961.00$ & 8.93 & 263.934 & 2 & $<.00001$ \\
\hline & Plasmodium falciparum & 437 & 454 & -17.00 & 289.00 & 0.64 & \multirow{2}{*}{\multicolumn{3}{|c|}{$\mathrm{H}_{04}$ rejected at alpha .05}} \\
\hline & Mixed & 10 & 274 & -264.00 & $69,696.00$ & 254.36 & & & \\
\hline & Total & 9,568 & 9,568 & \multicolumn{6}{|c|}{ Chi-square goodness of fit test with Yates correction } \\
\hline
\end{tabular}

$\mathrm{O}=$ Observed count, $\mathrm{E}=$ Expected count, $\chi^{2}=$ chi-square statistic, d.f. $=$ degree of freedom

Chi-square goodness of fit test showed $p$-value less than .05 alpha. $\mathrm{H}_{04}$ was declared to be false and hence rejected, showing that the observations did not match the expected values of the population. It simply means that our observed prevalence of malaria for Plasmodium vivax (8.38\%), Plasmodium falciparum $(0.40 \%)$ and mixed cases $(0.009 \%)$ was statistically not similar to what we expected for Plasmodium vivax (8.12\%), Plasmodium falciparum $(0.42 \%)$ and mixed cases $(0.25 \%)$ respectively (adjusted expected). (Table 3.2.4.2)

\section{DISCUSSION}

\subsection{Prevalence of malaria in suspected malarial population $\left(\mathrm{H}_{01}\right)$}

The prevalence of malaria in our study was $8.7901 \%$ (95\% Cl 8.62\%-8.95\%). Higher prevalence as per our $\mathrm{Cl}$ was reported in seven studies as follow; $63.33 \%$ by Abah, et al. ${ }^{7}, 61.05 \%$ by Eshag, et al. ${ }^{10}, 21.1 \%$ by Fatima, et al. ${ }^{16}, 17.14 \%$ by Al Mekhlafi, et al. ${ }^{9}, 16.58 \%$ by Singh, et al. ${ }^{11}, 13.843 \%$ by Qureshi, et al. ${ }^{15}$ and $13.81 \%$ by Najeeb, et al. ${ }^{14}$

Lower prevalence as per our $\mathrm{Cl}$ was reported in three studies as follow; $7 \%$ by Regassa, ${ }^{6} 5.76 \%$ by Directorate of Malaria Control (DMC), ${ }^{13}$ Islamabad for overall Pakistan for the year 2018 and 3.99\% by Kachur, et al. ${ }^{5}$

Ours calculations for percentages are correct as we have taken the sample i.e. all the suspected malarial cases of 6,500,000 as denominator, while DMC report has taken only positive cases as denominator.

No study could be found showing prevalence of malaria similar to our study.

Our observed prevalence of malaria $8.79 \%$ in suspected malarial population from a sample of 108,849 was lower $(p=<0.00001)$ than what we expected as $13.843 \%$ (adjusted expected) from Qureshi, et al. ${ }^{15}$ from a sample of 31,041. (Table 3.2.1.2). No relevant studies with hypotheses testing were available for comparison.

4.2 Distribution of positive cases of malaria in suspected malarial population by $\operatorname{sex}\left(\mathrm{H}_{02}\right)$

The prevalence of malaria in our study was more in men $4.97 \%$ (95\% Cl 4.83\%-5.09\%) than women $3.82 \%$ (95\% Cl 3.70\%-3.93\%). Higher prevalence as per our $\mathrm{Cl}$ was reported for men in five studies as follow; $36 \%$ by Abah, et al. ${ }^{7}, 27.89 \%$ by Eshag, et al. ${ }^{10}$, $10.58 \%$ by Singh, et al. ${ }^{11}, 10.55 \%$ by Al Mekhlafi, et al. ${ }^{9}$ and $6.75 \%$ by Qureshi, et al. ${ }^{15}$ Lower prevalence as per our $\mathrm{Cl}$ for men was reported $4 \%$ by Regassa. ${ }^{6}$

Higher prevalence as per our $\mathrm{Cl}$ for women was reported in five studies as follow; 33.15\% by Eshag, et al. ${ }^{10}, 27.33 \%$ by Abah, et al. ${ }^{7}, 7.09 \%$ by Qureshi, et al. ${ }^{15}, 6.54 \%$ by Al Mekhlafi, et al. ${ }^{9}$ and $6.00 \%$ by Singh, et al. ${ }^{11}$ Lower prevalence as per our $\mathrm{Cl}$ for women was reported $3 \%$ by Regassa. ${ }^{6}$

No study could be found showing distribution of malaria by sex similar to our study.

Our observed prevalence of malaria (from a sample of 108,849 ) in men $4.97 \%$ was statistically higher than what we expected for men $4.29 \%$ (adjusted expected) \& our observed prevalence of malaria in women $3.82 \%$ was statistically lower than what we expected for women $4.50 \%$ (adjusted expected) from a study by Qureshi, et al. ${ }^{15}$ from a sample of 31,041 from Khyber Pakhtunkhwa, Pakistan (Table 3.2.2.1). No relevant studies with hypotheses testing were available for comparison.

4.3 Distribution of positive cases of malaria in suspected malarial population by age groups $\left(\mathrm{H}_{03}\right)$ The prevalence of malaria by age groups in our study was more in age group $>5$ years $7.81 \%$ (95\% $\mathrm{Cl} 7.65 \%-7.97 \%)$ than in age group up to 5 years $0.98 \%$ (95\% Cl 0.91\%-1.03\%).

Higher prevalence as per our $\mathrm{Cl}$ in age group $>5$ years was reported in a study as $12.40 \%$ by Qureshi, et al. ${ }^{15}$ Lower prevalence as per our $\mathrm{Cl}$ in age group $>5$ years was reported in a study as $3.32 \%$ by Kachur, et al. ${ }^{5}$

Higher prevalence as per our $\mathrm{Cl}$ in age group up to 5 years was reported in a study as $1.44 \%$ by Qureshi, et al. ${ }^{15}$ Lower prevalence as per our $\mathrm{Cl}$ in age group up to 5 years was reported in a study as $0.67 \%$ by Kachur, et al. ${ }^{5}$

No study could be found showing distribution of malaria by age groups with count and percentages similar to our study.

Our observed prevalence of malaria (from a sample of $108,849)$ in age group $>5$ years $7.81 \%$ was statistically lower than what we expected for age group $>5$ years $7.87 \%$ (adjusted expected) \& our observed prevalence of malaria in age group up to 5 years $0.98 \%$ was statis- 
tically higher than what we expected for age group up to 5 years $0.92 \%$ (adjusted expected) from a study by Qureshi, et al. ${ }^{15}$ from a sample of 31,041 from Khyber Pakhtunkhwa. (Table 3.2.3.2). No relevant studies with hypotheses testing were available for comparison.

4.4 Distribution of positive cases of malaria in suspected malarial population by species $\left(\mathrm{H}_{04}\right)$

The prevalence of malaria by species in our study was $8.38 \%$ (95\% Cl $8.21 \%-8.54 \%)$ for Plasmodium vivax, $0.40 \%$ (95\% Cl 0.36\%-0.43\%) for Plasmodium falciparum and $0.009 \%$ (95\% Cl 0.0034\%-0.0148\%) for mixed cases.

Higher prevalence as per our $\mathrm{Cl}$ for Plasmodium vivax was reported in three studies as follow; $16.9 \%$ by Fatima, et al. ${ }^{16}, 12.79 \%$ by Qureshi, et al. ${ }^{15}$ and $9.08 \%$ by Singh, et al. ${ }^{11}$ Lower prevalence as per our $\mathrm{Cl}$ for Plasmodium vivax was reported in three studies as follow; $4.83 \%$ by DMC, ${ }^{13} 1.75 \%$ by Regassa ${ }^{6}$ and $0.44 \%$ by Al Mekhlafi, et al. ${ }^{9}$

Higher prevalence as per our $\mathrm{Cl}$ for Plasmodium falciparum was reported in six studies as follow: $16.4 \%$ by Al Mekhlafi, et al. ${ }^{9}, 4.5 \%$ by Regassa ${ }^{6}, 2.95 \%$ by Singh, et al. ${ }^{11}, 2.3 \%$ by Fatima, et al. ${ }^{16}, 0.86 \%$ by $\mathrm{DMC}^{13}$ and $0.66 \%$ by Qureshi, et al. ${ }^{15}$

Higher prevalence as per our $\mathrm{Cl}$ for mixed species was reported in five studies as follow; $4.55 \%$ by Singh, et al. ${ }^{11}, 1.2 \%$ by Fatima, et al. ${ }^{16}, 0.75 \%$ by Regassa ${ }^{6}$ $0.40 \%$ by Qureshi, et al. ${ }^{15}$ and $0.066 \%$ by DMC. ${ }^{13}$ No mixed cases were reported by Al Mekhlafi, et al. ${ }^{9}$

No study could be found showing distribution of malaria by species similar to our study.

Our observed prevalence of malaria (from a sample of 108,849 ) for Plasmodium vivax $8.38 \%$ was higher than what we expected for Plasmodium vivax $8.12 \%$ (adjusted expected) \& our observed prevalence for Plasmodium falciparum $0.40 \%$ was lower than what we expected for Plasmodium falciparum $0.42 \%$ (adjusted expected) and our observed prevalence for mixed cases $0.009 \%$ was lower than what we expected for mixed cases $0.25 \%$ (adjusted expected) from a study by Qureshi, et al. ${ }^{15}$ (Table 3.2.4.2). No relevant studies with hypotheses testing were available for comparison.

4.5 Marwat's Logical Trajectory of Research Process: This research project was designed by following the innovative and logical format of "Marwat's Logical Trajectory of Research Process". Many articles are published on this format in Gomal Journal of Medical Sciences. ${ }^{22-26}$

\section{CONCLUSIONS}

The prevalence of malaria in suspected malarial population of District D.I.Khan, Pakistan was $8.79 \%$. The prevalence of malaria was lower than expected for our population. The prevalence was more in men, more in older age group ( $>5$ years) and mostly caused by Plasmodium vivax. The prevalence for men was higher than expected for men and vice versa for women. The prevalence for age group up to 5 years was higher than expected for age group up to 5 years and vice versa for age group $>5$ years. The prevalence for Plasmodium vivax was higher than expected for Plasmodium vivax and vice versa for Plasmodium falciparum and mixed cases.

Acknowledgement: We are highly thankful to Dr. Muhammad Marwat (marwatmuhammad@gmail.com) for his overall supervision and active participation and guidance throughout this project, starting from conception through proposal writing, data collection, analysis and interpretation and manuscript writing. We are also obliged to him by granting us permission to adopt his "Marwat's Logical Trajectory of Research Process" for this project.

\section{REFERENCES}

1. David CP. Medical definition of malaria [accessed 2020 Nov 22]. MedicineNet. Available at: https:// www.medicinenet.com/script/main/art.asp?articlekey $=4255$

2. World Malaria Report 2020 [accessed 2020 Nov 30]. WHO, Geneva. Available at: https://www.who. int/publications-detail-redirect/97892400157913

3. Global Health Estimates 2015: Deaths by cause, age, sex, by country and by region, 2000-2015. Geneva, World Health Organization 2016 [cited 2020 Nov 22]. Available from: http://www.who.int/ healthinfo/global_burden_disease/estimates/en/ index1.html

4. Global Health Estimates 2015: Disease burden by cause, age, sex, by country and by region, 20002015. Geneva, World Health Organization 2016 [cited 2020 Nov 22]. Available at: http://www.who. int/healthinfo/global_burden_disease/estimates/ en/index2.html

5. Kachur SP, Nicolas E, Jean-François V, Benitez A, Bloland PB, Jean YS. Prevalence of malaria parasitemia and accuracy of microscopic diagnosis. Pan Am J Public Health 1998; 3(1): 35-9. Available at: https://www.scielosp.org/article/rpsp/1998. v3n1/35-39

6. Regasa B. Magnitude of malaria infection in Ethiopia. Global J Med Res 2014; 14(7). Available at: https://www.researchgate.net/profile/Belayneh-Regassa/publication/332752787_Magnitude_of_Malaria_Infection_in_Ethiopia

7. Abah AE, Temple B. Prevalence of Malaria Parasite among asymptomatic primary school children in Angiama community, Bayelsa State, Nigeria. Trop Med Surg 2015; 4(1): 203. https://doi. org/10.4172/2329-9088.1000203

8. WHO. EMRO. Malaria control and elimination. Malaria in the Eastern Mediterranean Region [accessed 2020 Nov 20]. WHO, Geneva. Available at: http://www.emro.who.int/malaria/about/ malaria-in-the-eastern-mediterranean-region.html

9. Al-Mekhlafi AM, Al-Mekhlafi HM, Mahdy MA, Azazy AA, Fong MY. Human malaria in the highlands of Yemen. Ann Trop Med Parasitol 2011 Apr; 105(3):187-95. https://doi.org/10.1179/13648591 1X12987676649421 
10. Eshag HA, Elnzer E, Nahied E, Talib M, Mussa A, Muhajir AEMA, et al. Molecular epidemiology of malaria parasite amongst patients in a displaced people's camp in Sudan. Trop Med Health 2020 Jan 29; 48:3. https://doi.org/10.1186/s41182-0200192-3

11. Singh G, Urhekar AD, Maheshwari U, Sharma S, Raksha. Prevalence of Malaria in a Tertiary Care Hospital in Navi Mumbai, India. J Bacteriol Parasitol 2015 Apr 7; 6(2):221. https://doi.org/10.4172/21559597.1000221

12. WHO. EMRO. Pakistan. Malaria and other vector-borne diseases [accessed 2020 Nov 20]. WHO, Geneva. Available at: http://www.emro.who.int/ pak/programmes/roll-back-malaria.html

13. Directorate of Malaria control, Islamabad. Pakistan Malaria Annual Report 2019 [accessed 2020 Nov 20]. Available at: http://dmc.gov.pk/documents/ pdfs/Pakistan\%20Malaria\%20Annual\%20Report\%202019\%20(002).pdf

14. Najeeb UK, Ali Z, Muhammad W, Saqib E, Iftikhar UD, Fazle $H$, Qazi AA. Incidence of malaria in Khyber Pakhtunkhwa, Pakistan: a Meta-Analysis. Ann Rev Resear 2018 Sep; 3(4): 93-9.

15. Qureshi H, Khan MI, Ambachew H, Pan HF, Ye DQ. Baseline survey for malaria prevalence in Khyber Pakhtunkhwa Province, Pakistan. East Mediterr Health J 2020 April 16;26(4):453-60. https://doi. org/10.26719/emhj.19.015

16. Jahan F, Khan NH, Wahid S, Ullah Z, Kausar A, Ali N. Malaria epidemiology and comparative reliability of diagnostic tools in Bannu; an endemic malaria focus in south of Khyber Pakhtunkhwa, Pakistan. Pathog Glob Health 2019 Mar 21; 113(2):75-85. https://doi.org/10.1080/20477724.2019.1595904

17. Wikipedia. Dera Ismail Khan District [accessed 202 Nov 20]. Available at: https://en.wikipedia.org/wiki/ Dera_Ismail_Khan_District

18. PAKNGOs. Frontier Primary Health Care -FPHC [accessed 202 Nov 20]. Available at: https://pakngos. com.pk/listing/frontier-primary-health-care-fphc/
19. Raosoft $₫$ online sample size calculator [Internet]. Raosoft Inc., Seattle, Washington 2004. [accessed 2020 Nov 20]. Available from: www.raosoft.com/ samplesize.html

20. Statistics Kingdom. Proportion confidence interval calculator [internet]. Statistics Kingdom; Melbourne, Australia 2007. [accessed 2020 Nov 22]. Available at: https://www.statskingdom. com/41_proportion_confidence_interval.html

21. Social Science Statistics. Statistical Tests Calculators [Internet]. [accessed 2020 Nov 22]. Available from: https://www.socscistatistics.com/tests/ goodnessoffit/default2.aspx

22. Shah S, Basharat A, Shah M, Marwat M, Billah M, Ali SM. Frequency, distribution and presentation $\mathrm{n}$ of hypocalcemia in B-thalassemia major. Gomal J Med Sci 2018; 16:2-8. https://doi.org/10.46903/ gjms/16.01.1446

23. Ghori MR, Khan H, Marwat M. Distribution of non-malignant hematological disorders by sex, age groups and type of disease based on bone marrow aspiration in population of Khyber Pakhtunkhwa, Pakistan. Gomal J Med Sci 2019 Apr-Jun; 17 (2): 29-36. https://doi.org/10.46903/gjms/17.02.1926

24. Ain N, Khan S, Marwat M, Khan N, Ahmad I, Ramzan F, et al. Frequency, distribution and determinants of hypertension in adult stroke population of D.I.Khan Division, Pakistan. Gomal J Med Sci 2019 Jul-Sep; 17 (3):81-9. https://doi. org/10.46903/gjms/17.03.2076

25. Marwat M, Ahmad I, Ashiq F, Ali S, Zamir S, Rehman $\mathrm{MU}$, et al. Frequency, distribution and determinants of diabetes mellitus in adult acute coronary syndrome population of D.I.Khan Division, Pakistan. Gomal J Med Sci 2019 Oct-Dec; 17 (4):131-43. https://doi.org/10.46903/gjms/17.04.2106

26. Khalid MK, Ahmad I, Khan MA, Sharjeel M, Irfan M. Marwat M. Distribution of pediatric cataracts by sex, age groups, laterality, type and presentation in population of D.I.Khan District, Pakistan. Gomal J Med Sci 2019 Oct-Dec; 17 (3):123-30. https://doi. org/10.46903/gjms/17.04.2025

\section{CONFLICT OF INTEREST \\ Authors declare no conflict of interest. GRANT SUPPORT AND FINANCIAL DISCLOSURE None declared.}

\section{AUTHORS' CONTRIBUTION}

The following authors have made substantial contributions to the manuscript as under:

Conception or Design:

Acquisition, Analysis or Interpretation of Data:

Manuscript Writing \& Approval:

All the authors agree to be accountable for all aspects of the work in ensuring that questions related to the accuracy or integrity of any part of the work are appropriately investigated and resolved.
SWAN, SS, AR, MHS, NK, AK

SWAN, SS, AR, MHS, NK, AK, MU, MUF, HAHK, RA

SWAN, SS, AR, MHS, NK, AK, JW, MKB, AEZ, FR 